\title{
Tick Abundance and Levels of Infestation on Cattle in Response to Patch Burning
}

\author{
Victoria J. Polito, ${ }^{1}$ Kristen A. Baum, ${ }^{2}$ Mark E. Payton, ${ }^{3}$ Susan E. Little, ${ }^{4}$ Samuel D. Fublendorf, ${ }^{5}$ and \\ Mason V. Reichard ${ }^{6}$
}

Authors are ${ }^{1}$ Graduate Teaching Assistant, ${ }^{4}$ Professor, and ${ }^{6}$ Associate Professor, Department of Veterinary Pathobiology, ${ }^{2}$ Associate Professor, Department of Zoology, ${ }^{3}$ Professor, Department of Statistics, and ${ }^{5}$ Professor, Department of Natural Resource Ecology and Management, Oklahoma State University, Stillwater, OK 74078, USA.

\begin{abstract}
Patch burning $(\mathrm{PB})$ uses frequent, spatially discrete fires throughout a pasture to create variation in the composition and structure of the plant community. The complex vegetation changes incurred from this type of burning regimen in addition to the focal grazing of cattle induced by PB should reduce tick populations by creating less favorable microhabitats. To determine if a reduction in tick populations occurred on $\mathrm{PB}$ pastures, three PB-treated pastures and three control pastures were used. $\mathrm{PB}$ pastures were divided into six subplots with one burned rotationally each spring and summer. Control pastures and each $\mathrm{PB}$ subplot had a burn interval of 3 yr. Pastures were dragged with $1-\mathrm{m}^{2}$ flannel cloth panels to estimate tick abundance for 4 yr. (2006, 2007, 2009, and 2010). Infestation levels with ticks (i.e., tick burden) and weight for five calves and three cows per pasture were recorded once a month from April to October in 2009, 2010, and 2011. Differences in tick abundance between PB pastures and control pastures were not significant except in 2006 when fewer adult ticks were detected in PB pastures. A total of 13609 ticks were observed on cattle. Animals on PB pastures had 4028 (29.6\%) ticks whereas 9581 (70.4\%) ticks were on cattle from control pastures. Tick burden was significantly reduced on animals in PB pastures compared to animals in control pastures in 4 out of 6 mo. Significant differences in average daily weight gain of calves in PB and control pastures were not detected. Although differences were not detected in questing tick abundance on pastures, significant reductions of tick burden on cattle in PB-treated pastures indicates that PB can be used to help control ticks in pastures.
\end{abstract}

Key Words: Amblyomma americanum, cattle infestation, Oklahoma, prescribed burn, ticks

\section{INTRODUCTION}

Ticks are obligate blood-feeding parasites that can induce a variety of negative effects on cattle. Severe infestations by ticks on cattle can cause reduced weight gains, irritation, pruritus, gotch ear, and stress (Stacey et al. 1978; Williams et al. 1978; Byford et al. 1992; Jonsson et al. 1998; Tolleson et al. 2010). Ticks can also vector bacterial, rickettsial, viral, and protozoal disease agents (de Castro and Newson 1993; Jongejan and Uilenberg 2004). Losses to the cattle industry in the UnitedStates from Amblyomma americanum L. (lone star tick), one of the most abundant ticks in Oklahoma, were estimated at $\$ 82$ million in 1987, which is equivalent to over $\$ 165$ million in 2012 (Clymer et al. 1970; Drummond 1987).

Due to the threat ticks and tick-borne disease agents pose to cattle and other animals, various control methods have been implemented. Application of acaricides, the most commonly used method, has had problems with resistance, and the cost to develop a new antiparasitic drug has been estimated to exceed $\$ 100$ million in 2004, which would now equal more than $\$ 121$ million (Graf et al. 2004; Willadsen 2006; de la Fuente et al.

Research was funded in part by the United States Department of Agriculture Managed Ecosystems Project (Award Number: 2009-35101-05170) and the Center for Veterinary Health Sciences, Oklahoma State University.

Correspondence: Dr Mason V. Reichard, Center for Veterinary Health Sciences, Oklahoma State University, Stillwater, OK 74078, USA. Email: mason.reichard@ okstate.edu

Manuscript received 16 November 2012; manuscript accepted 24 June 2013

(c) 2013 The Society for Range Management
2007). Because of acaricide resistance and drug development costs, interest in the use of prescribed burning as a means of natural tick control has increased (Jacobson and Hurst 1979; Warren et al. 1987; Scifres et al. 1988; Davidson et al. 1994; Cully 1999).

Ticks can be killed directly through combustion when a prescribed burn occurs. However, long lasting effects of burns result from the removal of protective leaf litter layers and changes in vegetation that reduce the availability of microhabitats that ticks use as refugia to escape harsh environmental conditions (Scifres et al. 1988; Davidson et al. 1994; Cully 1999; Fuhlendorf and Engle 2004). Ticks are sensitive to fluctuations in temperature and relative humidity $(\mathrm{RH})$ and are at risk for desiccation when exposed to unfavorable conditions (e.g., high temperatures and low RH) for extended periods of time (Harlan and Foster 1986, 1990; Chilton and Bull 1994; Bertrand and Wilson 1997; Schulze and Jordan 2003).

Favorable tick microhabitats contain a layer of leaf litter and accumulated biomass that retain moisture. After losing 4-5\% of their body weight to evaporation during unsuccessful questing attempts, ticks return to the leaf litter to rehydrate (Harlan and Foster 1990). Lone star ticks actively reabsorb moisture through their water up-take system when RH drops below 74-89\% (Needham and Teel 1991). When a humid refuge above this RH is not available to ticks, they are at risk for desiccation. Reduction in leaf litter and protective vegetation through burning leads to a general drying in the environment (Warren et al. 1987; Scifres et al. 1988). Because three-host ixodid (i.e., hard) ticks spend $94-97 \%$ of their life off their vertebrate hosts in the environment (Needham and 
Teel 1991), application of prescribed burning in cattle pastures could be used as a natural method of tick control.

Patch burning $(\mathrm{PB})$ entails dividing one pasture into smaller subplots to which spatially discrete fires are rotationally applied. Along with focal grazing of ruminants, this strategy creates variation in the composition and structure of the plant community (Fuhlendorf and Engle 2004; Vermeire et al. 2004). In previous $\mathrm{PB}$ work, cattle spent $75 \%$ of their time in the most recently burned subplots (Fuhlendorf and Engle 2004; Vermeire et al. 2004). In recently burned subplots, the plant community structure and composition might not provide suitable microhabitats for ticks because these areas have less leaf litter and more exposure to direct sunlight and wind because of the presence of bare ground. These conditions cause water stress in ticks, which affects tick survival and behavior (Cully 1999). We hypothesized that $\mathrm{PB}$ would alter the vegetation structure in cattle pastures to negatively affect tick populations and reduce the number of ticks on cattle. To test this hypothesis, we compared questing tick abundance in pastures and infestation levels of ticks on cattle (i.e., tick burden) between three PBtreated and three control pastures burned completely every 3 yr.

\section{MATERIALS AND METHODS}

\section{Study Site}

Research sites were located at the Oklahoma State University (OSU) Research Range located $21 \mathrm{~km}$ southwest of Stillwater, Oklahoma in north central Oklahoma. The OSU Research Range is predominantly tall-grass prairie. In the present study, six pastures varying in size from 45 to 65 ha were used. Three of these pastures were used as PB-treated pastures and three as controls. $\mathrm{PB}$ pastures were divided into six subplots, with each subplot measuring approximately $200 \mathrm{~m} \times 400 \mathrm{~m}$. One subplot was burned each spring (March to May) and one subplot was burned each summer (July to September), creating a burn return interval of $3 \mathrm{yr}$. Control pastures were burned in their entirety once every $3 \mathrm{yr}$ in the spring. This 3 -yr burn regime was chosen as a control because it had the same burn return interval as each PB subplot. Unburned pastures were not used as controls because woody vegetation encroachment can occur and result in distinct structural differences between the treatment and control pastures (Warren et al. 1987). Pastures were moderately grazed year-round by mixed cow/calf and yearling herds.

\section{Tick Abundance in Pastures}

Questing tick abundance was monitored in treatment and control pastures in 2006, 2007, 2009, and 2010. Thirty-three, 2-m-wide transects were identified in each pasture and evenly spaced $10 \mathrm{~m}$ apart. The order transects were sampled was randomly chosen using a random number generator, but no transect was sampled more than once in a year. Three transects were sampled twice a month in April, May, and June and three transects were sampled once a month in March, July, August, September, and October. Months sampled twice were those with highest levels of tick activity (Wright and Barker 2006). In treatment pastures, all six subplots were sampled, whereas only two subplots were sampled in control pastures. Surveys were restricted to the period from $2 \mathrm{~h}$ after sunrise to $2 \mathrm{~h}$ before sunset and were not conducted during or immediately after periods of precipitation. Transects oriented in a north-south bearing were sampled using $1-\mathrm{m}^{2}$ cloth panel drags. Workers walked down and back the entire length of the pasture, resulting in a 2-m-wide transect. Flannel cloth panels were visually checked every $30 \mathrm{~m}$ for ticks. Tick species and life stage were recorded. Workers dragging transects were guided by handheld GPS units. When heavy tree canopies interfered with satellite signals, hand-held compasses were used to maintain a straight heading.

Data were analyzed with SAS Version 9.2 (SAS Institute, Cary, NC). Tick numbers for all life stages were logtransformed to normalize the values and equalize variances to meet assumptions for conducting analyses of variance (ANOVA). Simple effects of treatment given year or subplots were assessed using a two-factor model. Pasture was considered a blocking variable. Significance was determined at a 0.05 level.

\section{Tick Burden on Cattle}

Cattle infestation with ticks was monitored over 3 yr (20092011). Cattle were randomly chosen for sampling at the first observation of the year and individuals were only sampled for a single year. Within a year, the same three adult cows and five calves were sampled from each pasture once a month starting in the spring (April) and continuing through the fall (October). Cattle were permanently identified by ear tags and were randomly assigned to a treatment or control pasture with free access within their assigned area. Tick counts on cattle were typically performed over a 2-d period: three pastures per day except on the last count of the season when all cattle were brought to OSU Research Range headquarters to wean calves from adult cows and counts were done on the same day. Cattle were held in holding pens for no more than $24 \mathrm{hr}$ before tick burden was estimated. Cattle were individually run through a squeeze chute, which had panels that could be opened to provide easy access to the entire body of each individual.

Only ticks on the right side of the body were counted and identified due to time constraints. In the first year of the study, all ticks were removed from the cattle and placed in labeled vials with $70 \%$ ethanol for later identification. In the subsequent $2 \mathrm{yr}$, ticks were counted and identified in the chute and left on cattle. Life stage and species of each tick were identified to the nymphal stage by visual inspection and all larvae were placed into the "unidentified" category because they could not be reliably identified while still attached to cattle. A magnifying glass was used to help determine species of ticks using tick identification keys (Clifford et al. 1960; Diamant and Strickland 1965; Strickland et al. 1976; Keirans and Litwak 1988; Keirans and Durden 1998).

Cattle weights were recorded using a weigh tape (Dupont, Wilmington, DE) read by the same individual within a given year. A weigh tape was used to estimate cattle weights because calibrated livestock weigh scales were not available over the course of the study. Although this method did not provide the most accurate measurement, using a weigh tape allowed for comparisons between animals on control and PB treatment pastures. 
Table 1. Abundance (mean $\pm \mathrm{SE}$ ) of ticks recovered by cloth panel dragging in patch-burned $(\mathrm{PB})$ and control pastures from March to 0ctober in 2006, 2007, 2009, and 2010 .

\begin{tabular}{|c|c|c|c|c|c|c|c|c|c|}
\hline \multirow[b]{2}{*}{ Year } & \multirow[b]{2}{*}{ Pasture } & \multicolumn{2}{|c|}{ Adult } & \multicolumn{2}{|c|}{ Nymph } & \multicolumn{2}{|c|}{ Larvae } & \multicolumn{2}{|c|}{ Overall } \\
\hline & & Mean \pm SE & $P^{1}$ & Mean \pm SE & $P^{1}$ & Mean \pm SE & $P^{1}$ & Mean \pm SE & $P^{1}$ \\
\hline 2006 & Control & $27.3 \pm 4.7$ & 0.011 & $14.7 \pm 4.4$ & 0.417 & $121.5 \pm 121.5$ & 0.487 & $163.5 \pm 121.6$ & 0.319 \\
\hline \multirow[t]{2}{*}{2007} & Control & $5.5 \pm 1.9$ & 0.639 & $3.2 \pm 1.2$ & 0.367 & $417.0 \pm 193.4$ & 0.460 & $425.7 \pm 193.9$ & 0.440 \\
\hline & PB & $4.2 \pm 0.9$ & & $5.3 \pm 1.9$ & & $344.3 \pm 145.3$ & & $353.7 \pm 147.2$ & \\
\hline 2009 & Control & $21.2 \pm 7.9$ & 0.247 & $86.8 \pm 36.2$ & 0.432 & $772.0 \pm 321.1$ & 0.779 & $880.0 \pm 322.9$ & 0.437 \\
\hline \multirow[t]{2}{*}{2010} & Control & $8.6 \pm 3.1$ & 0.865 & $4.8 \pm 1.1$ & 0.310 & $0.1 \pm 0.1$ & $N A^{2}$ & $13.5 \pm 3.8$ & 0.710 \\
\hline & PB & $8.6 \pm 2.1$ & & $10.9 \pm 3.1$ & & $0.0 \pm 0.0$ & & $19.5 \pm 4.9$ & \\
\hline
\end{tabular}

${ }_{1}^{1} P$ values reflect the comparison of questing tick abundance in PB and control pastures for each respective sampling period.

${ }^{2} \mathrm{NA}$ indicates not applicable.

Cattle were treated twice yearly with $10 \mathrm{ml}$ of $1 \% \mathrm{w} / \mathrm{v}$ injectable doramectin (10 $\mathrm{mg} \cdot \mathrm{ml}^{-1}$ Dectomax Injectable Solution; Pfizer Animal Health, Exton, PA). One treatment was given in the spring and one treatment in the fall. Doramectin is not labeled for use to control ticks on cattle but has been shown to be effective in controlling arthropods (George et al. 2004; Lohmeyer et al. 2009). Spring treatments were administered immediately after the first tick count on cattle while cattle were still in the squeeze chutes in April. Fall deworming treatments were given after the final cattle infestation observation and therefore did not affect tick burden counts.

Data were analyzed with SAS Version 9.2 (SAS Institute). Repeated measures ANOVA with an autoregressive covariance structure was performed on the number of ticks to compare PBtreated pasture animals and control pasture animals. Years were used as replicates, and month was the repeated measures factor. Average daily weight gain (ADG) was also compared using repeated measures ANOVA with an unstructured covariance structure. Simple effects of treatment given month (or time) were assessed. Statistical significance was determined at the 0.05 level.

\section{RESULTS}

\section{Tick Abundance in Pastures}

The abundance of questing ticks was estimated for 4 yr (2006, 2007, 2009, and 2010). Overall, no difference was observed in the total number of ticks from PB pastures and control pastures during the $4 \mathrm{yr}$ of sampling (Table 1). No differences were detected in number of larvae or the number of nymphs recovered from $\mathrm{PB}$ pastures and control pastures. Adult ticks were significantly reduced in $\mathrm{PB}$ pastures compared to control pastures in $2006(\mathrm{~F}=7.81, \mathrm{df}=1, P=0.011$; Table 1$)$. No other year had a significant difference between the numbers of adult ticks. Analysis was not performed for larvae in 2010 because no larval ticks were recovered from PB-treated pastures and very few were recovered from control pastures that year. Differences in tick abundance were not detected among subplots with different seasons and times since burn within PB pastures. Similarly, significant differences between the number of nymphs or the number of larvae recovered in $\mathrm{PB}$ pasture subplots were not detected with the exception of adult ticks in $2007(\mathrm{~F}=4.83, \mathrm{df}=5, P=0.022$; Table 1$)$.

\section{Tick Burden on Cattle}

A total of 13609 ticks were observed on cows and calves over the course of the study. The most commonly observed ticks (Table 2) were Amblyomma americanum (74.3\%), A. maculatum Koch (7.1\%), and unidentified species (16.5\%). Few Dermacentor albipictus Packard (0.4\%) and Ixodes scapularis Say $(<1 \%)$ were recovered. Ticks categorized as "unidentified" species were mainly larval ticks. Larvae were small and difficult to identify to genus without the use of a dissecting microscope. However, in 2009 all ticks were removed from cattle and identified to species in the laboratory. Almost all larvae removed from cattle in 2009 were A. americanum larvae (Table 2). Adult ticks were the most common life stage observed on cattle with 7959 of 13609 (58.5\%) ticks being adults. Nymphs were the second most common with 3261 of 13609 (24\%), followed by larvae with 2389 of 13609 $(17.5 \%)$.

More than twice as many ticks were found on cows and calves from control pastures than on animals from PB pastures (Table 3). On average, adult cows on PB pastures were infested with 242.9 ticks per individual, whereas adult cows on control pastures were infested with 598.6 ticks per individual (Table 3). Calves in control pastures also had more than twice the number of ticks as calves on PB pastures. Calves in PB pastures had on average 122.8 ticks per individual and calves in control pastures had 279.6 ticks per individual (Table 3).

Of the 13609 ticks counted, 9581 (70.4\%) were observed on animals from control pastures. Only 4028 (29.6\%) were observed on animals from PB pastures. This trend of $70 \%$ to $30 \%$ control versus $\mathrm{PB}$ treatment of ticks on cattle was observed regardless of the time since burn in the control pastures (i.e., even during the year that the control pastures were burned).

Significantly fewer ticks (all life stages) were recovered from calves in PB pastures compared to calves in control pastures in May, June, July, and September $(\mathrm{F}=5.93, \mathrm{df}=1, P=0.018$; $\mathrm{F}=13.28, \mathrm{df}=1, P=0.0005 ; \mathrm{F}=4.77, \mathrm{df}=1, P=0.033$; and $\mathrm{F}=6.84, \mathrm{df}=1, P=0.011$, respectively; Table 4$)$. Infestation by adult ticks on calves in $\mathrm{PB}$ pastures was significantly lower in May and June $(\mathrm{F}=7.21, \mathrm{df}=1, P=0.009$; and $\mathrm{F}=25.57, \mathrm{df}=1$, 
Table 2. Number of ticks by species recovered from cows and calves on patch-burned (PB) and control pastures in 2009, 2010 , and 2011.

\begin{tabular}{|c|c|c|c|c|c|c|c|c|}
\hline \multirow[b]{2}{*}{ Tick } & \multicolumn{2}{|c|}{ Adult } & \multicolumn{2}{|c|}{ Nymph } & \multicolumn{2}{|c|}{ Larvae $^{1}$} & \multirow[b]{2}{*}{ Total } & \multirow[b]{2}{*}{ Percentage } \\
\hline & PB & Control & PB & Control & PB & Control & & \\
\hline Amblyomma americanum & 2172 & 5144 & 807 & 1838 & 57 & 101 & 10119 & $74.3 \%$ \\
\hline A. maculatum & 171 & 299 & 72 & 426 & 2 & 3 & 973 & $7.1 \%$ \\
\hline Dermacentor variabilis & 46 & 68 & 4 & 87 & 3 & 0 & 208 & $1.5 \%$ \\
\hline D. albipictus & 33 & 13 & 2 & 4 & 0 & 0 & 52 & $0.4 \%$ \\
\hline Ixodes scapularis & 8 & 4 & 0 & 0 & 0 & 0 & 12 & $<0.1 \%$ \\
\hline Unidentified & 0 & 1 & 3 & 18 & 648 & 1575 & 2245 & $16.5 \%$ \\
\hline Total & 2430 & 5529 & 888 & 2373 & 710 & 1679 & 13609 & \\
\hline Percentage & $17.9 \%$ & $40.6 \%$ & $6.5 \%$ & $17.5 \%$ & $5.2 \%$ & $12.3 \%$ & & \\
\hline
\end{tabular}

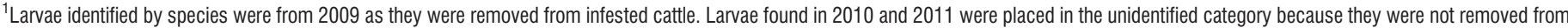
cattle and could not be readily identified while attached to their host.

$P=<0.0001$, respectively) than on calves in control pastures (Table 4). Level of infestation by nymphs on calves in PB pastures was less in May, June, and September $(\mathrm{F}=7.53, \mathrm{df}=1$, $P=0.009 ; \mathrm{F}=11.11, \mathrm{df}=1, P=0.002 ;$ and $\mathrm{F}=4.07, \mathrm{df}=1$, $P=0.051$, respectively) compared to calves in control pastures and level of larvae was significantly less in July and September $(\mathrm{F}=7.17, \mathrm{df}=1, P=0.010$; and $\mathrm{F}=7.47, \mathrm{df}=1, P=0.009$; Table 4) on calves in $\mathrm{PB}$ pastures compared to on calves in control pastures.

Number of overall ticks (all life stages) infesting adult cows in $\mathrm{PB}$ pastures was significantly less in 4 out of the 6 mo observed compared to adult cattle in control pastures (Table 5). Differences occurred in April, May, June, and September $(\mathrm{F}=4.42, \quad \mathrm{df}=1, \quad P=0.037 ; \mathrm{F}=14.55, \mathrm{df}=1, \quad P=0.0002$; $\mathrm{F}=16.89, \mathrm{df}=1, P=0.0001 ;$ and $\mathrm{F}=16.89, \mathrm{df}=1, P=0.033$, respectively; Table 5). Fewer adult ticks on adult cows in $\mathrm{PB}$ pastures than on adult cattle in control pastures occurred in April, May, and June $(\mathrm{F}=6.86, \mathrm{df}=1, P=0.009 ; \mathrm{F}=23.31$, $\mathrm{df}=1, P=<0.0001 ;$ and $\mathrm{F}=25.14, \mathrm{df}=1, P=<0.0001$, respectively; Table 5). Level of infestation by nymphs on adult cattle in $\mathrm{PB}$ pastures was significantly less from level of infestation of nymphs on adult cattle in control pastures in May, June and September $(\mathrm{F}=6.40, \mathrm{df}=1, P=0.012 ; \mathrm{F}=20.56$, $\mathrm{df}=1, P=<0.0001$; and $\mathrm{F}=4.98, \mathrm{df}=1, P=0.028$, respectively). No differences were observed in the number of larvae on adult cows in PB versus control pastures for any month. Fewer larvae were detected in September $(\mathrm{F}=3.80, \mathrm{df}=1, P=0.056)$ for adult cows in $\mathrm{PB}$ pastures compared to adult cows on control pastures (Table 5).

The overall average daily gain for calves housed on $\mathrm{PB}$ pastures was $0.59 \pm 0.08 \mathrm{~kg} \cdot \mathrm{d}^{-1}$ and $0.60 \pm 0.06 \mathrm{~kg} \cdot \mathrm{d}^{-1}$ for control calves; this difference was not significant $(\mathrm{F}=0.40$, $\mathrm{df}=1, P=0.528)$. Similarly, differences in the monthly average daily gain of calves housed on PB pastures over the course of the study was not significantly different from those of calves on control pastures.

\section{DISCUSSION}

Amblyomma americanum is the most abundant tick found on cattle in Oklahoma (Clymer et al. 1970; Robertson et al. 1975). Clymer et al. (1970) found that 90\% (31 095 of 34550 ) of ticks collected in their study in east-central Oklahoma were $A$. americanum. A. americanum was also the most common $89.0 \%$ (10 119 of 11364 ) species on cattle in the current study. Adult ticks were the most common $(58.5 \%)$ life stage, followed by nymphs $(24 \%)$ and larvae $(17.5 \%)$. The high proportion of adult ticks is likely due in part to predilection of some species' juvenile stages to feed on smaller mammals (Clymer et al. 1970; Semtner and Hair 1973; Zimmerman et al. 1987; Wright and Barker 2006). For example, preferred hosts for A. maculatum larvae and nymphs in Oklahoma are bobwhite quail (Colinus virginianus L.), grasshopper sparrow (Ammodramus savannarum Gmelin), meadow lark (Sturnella sp.), cotton rat (Sigmodon hispidus Say and Ord), and deer mice (Peromyscus spp.; Semtner and Hair 1973; Barker et al. 2004). Dermacentor variabilis immature stages prefer to feed on small rodents (Zimmerman et al. 1987). Although D. albipictus is a one-host tick that preferentially feeds on cattle, horses, and deer, it is most common in Oklahoma from late fall to early spring (Clymer et al. 1970), and we did not focus on this time frame for our study. Ixodes scapularis immature stages typically feed on lizards, birds, and small mammals in Oklahoma and are also more active late fall (Clymer et al. 1970).

Because only cattle were sampled in the present study, we do not possess a complete view of the tick population within PB

Table 3. Total number of ticks recovered on cows and calves on patch-burned (PB) and control pastures by year. Numbers in parentheses represent average burden per individual animal.

\begin{tabular}{|c|c|c|c|c|c|c|c|}
\hline \multirow[b]{2}{*}{ Animal } & \multicolumn{2}{|c|}{2009} & \multicolumn{2}{|c|}{2010} & \multicolumn{2}{|c|}{2011} & \multirow[b]{2}{*}{ Total } \\
\hline & PB & Control & PB & Control & PB & Control & \\
\hline Cows & $860(286.7)$ & 1769 (589.7) & $704(234.7)$ & 1937 (645.7) & $622(207.3)$ & $1681(560.3)$ & 7573 \\
\hline Calves & 497 (99.4) & $1206(241.2)$ & $1001(200.2)$ & 2061 (412.2) & $344(68.8)$ & 927 (185.4) & 6036 \\
\hline Total & 1357 & 2975 & 1705 & 3998 & 966 & 2608 & 13609 \\
\hline
\end{tabular}


Table 4. Tick burden (mean number \pm SE) on calves by month in patch-burned (PB) and control pastures from April to 0ctober in 2009,2010 , and 2011.

\begin{tabular}{|c|c|c|c|c|c|c|c|c|c|}
\hline \multirow[b]{2}{*}{ Month } & \multirow[b]{2}{*}{ Pasture } & \multicolumn{2}{|c|}{ Adult } & \multicolumn{2}{|c|}{ Nymph } & \multicolumn{2}{|c|}{ Larvae } & \multicolumn{2}{|c|}{ Overall } \\
\hline & & Mean \pm SE & $P^{1}$ & Mean \pm SE & $P^{1}$ & Mean \pm SE & $P^{1}$ & Mean \pm SE & $P^{1}$ \\
\hline \multirow[t]{2}{*}{ April } & Control & $15.1 \pm 2.07$ & 0.104 & $9.7 \pm 2.69$ & 0.102 & $0.0 \pm 0.00$ & - & $35.3 \pm 4.23$ & 0.183 \\
\hline & PB & $11.6 \pm 1.28$ & & $4.9 \pm 1.17$ & & $0.0 \pm 0.00$ & & $25.7 \pm 3.12$ & \\
\hline \multirow[t]{2}{*}{ May } & Control & $11.8 \pm 1.87$ & 0.009 & $15.7 \pm 4.06$ & 0.009 & $0.1 \pm 0.09$ & 0.898 & $20.8 \pm 3.37$ & 0.018 \\
\hline & PB & $5.8 \pm 0.99$ & & $4.4 \pm 1.15$ & & $0.0 \pm 0.02$ & & $8.4 \pm 1.49$ & \\
\hline \multirow[t]{2}{*}{ June } & Control & $19.8 \pm 1.93$ & $<0.0001$ & $16.8 \pm 4.11$ & 0.002 & $0.0 \pm 0.00$ & - & $29.8 \pm 3.63$ & 0.0005 \\
\hline & $\mathrm{PB}$ & $8.7 \pm 1.08$ & & $6.3 \pm 2.01$ & & $0.0 \pm 0.00$ & & $12.2 \pm 1.94$ & \\
\hline \multirow[t]{2}{*}{ July } & Control & $5.8 \pm 0.98$ & 0.257 & $1.4 \pm 0.38$ & 0.456 & $10.5 \pm 3.13$ & 0.010 & $17.7 \pm 3.88$ & 0.033 \\
\hline & PB & $3.8 \pm 0.62$ & & $0.3 \pm 0.10$ & & $1.9 \pm 0.85$ & & $6.1 \pm 1.26$ & \\
\hline \multirow[t]{2}{*}{ August } & Control & $0.9 \pm 0.22$ & 0.855 & $5.1 \pm 1.42$ & 0.171 & $6.8 \pm 2.05$ & 0.646 & $12.8 \pm 2.89$ & 0.357 \\
\hline & $\mathrm{PB}$ & $0.9 \pm 0.17$ & & $1.9 \pm 0.58$ & & $6.6 \pm 2.42$ & & $9.4 \pm 2.76$ & \\
\hline \multirow[t]{2}{*}{ September } & Control & $0.4 \pm 0.12$ & 0.763 & $8.7 \pm 1.53$ & 0.051 & $9.1 \pm 2.12$ & 0.009 & $15.7 \pm 2.73$ & 0.011 \\
\hline & PB & $0.6 \pm 0.14$ & & $3.9 \pm 0.99$ & & $2.8 \pm 1.08$ & & $5.8 \pm 1.30$ & \\
\hline \multirow[t]{2}{*}{ October } & Control & $0.4 \pm 0.13$ & 0.895 & $0.8 \pm 0.26$ & 0.978 & $5.5 \pm 3.02$ & 0.290 & $6.5 \pm 3.08$ & 0.439 \\
\hline & PB & $0.3 \pm 0.09$ & & $0.7 \pm 0.18$ & & $1.9 \pm 0.69$ & & $2.7 \pm 0.74$ & \\
\hline
\end{tabular}

${ }_{1}^{1} P$ values reflect the comparison of tick burden on calves in $\mathrm{PB}$ and control pastures for each respective sampling period.

and control pastures. Juvenile and adult ticks might have been present on other hosts. A. americanum, the most commonly recovered tick, also feeds on white-tailed deer (Odocoileus virginianus Zimmerman) and coyotes (Canis latrans Say) as an adult and on wild turkeys (Meleagris gallopavo L.), whitetailed deer, and raccoons (Procyon lotor L.) during immature stages (Kollars et al. 2000). Preferred hosts for adult $A$. maculatum are also white-tailed deer, raccoons, and coyotes (Barker et al. 2004). D. variabilis is known for having little host specificity as an adult, but was the most commonly recovered tick from raccoons by Clymer et al. (1970). D. albipictus and I. scapularis adults also feed on white-tailed deer and raccoons (Clymer et al. 1970). These wild mammals were likely present in pastures at the OSU Research Range. Also, only ticks on the right side of cattle were counted. Bloemer et al. (1988) observed that adult ticks of $A$. americanum more often attached to the left side of the body of white-tailed deer, whereas larvae were more commonly found on the right side, and nymphs showed no significant preference. This side preference has not been shown in cattle and always sampling the same side of each animal maintained consistency in the results.

Significant differences in tick infestation were observed in months of peak tick burden for both adult cows and calves. Adult ticks were significantly reduced on animals in PB pastures in April (adult cows only), May, and June. This corresponds to the time when adult ticks are most active in Oklahoma (Clymer et al. 1970; Barker et al. 2004). Nymphs, which are most active spring and early summer, were significantly reduced in May, June, and September (adult cows only; Zimmerman et al. 1987). Larvae were reduced on PB pastures in July (calves only) and September (calves only), which is also when they are most

Table 5. Tick burden (mean number \pm SE) on adult cows by month in patch-burned (PB) and control pastures from April to 0ctober in 2009, 2010, and 2011.

\begin{tabular}{|c|c|c|c|c|c|c|c|c|c|}
\hline \multirow[b]{2}{*}{ Month } & \multirow[b]{2}{*}{ Pasture } & \multicolumn{2}{|c|}{ Adult Tick } & \multicolumn{2}{|c|}{ Nymph } & \multicolumn{2}{|c|}{ Larvae } & \multicolumn{2}{|c|}{ Overall } \\
\hline & & Mean \pm SE & $P^{1}$ & Mean \pm SE & $P^{1}$ & Mean \pm SE & $P^{1}$ & Mean \pm SE & $P^{1}$ \\
\hline \multirow[t]{2}{*}{ April } & Control & $29.0 \pm 4.89$ & 0.009 & $2.8 \pm 0.64$ & 0.373 & $0.0 \pm 0.00$ & - & $59.6 \pm 10.01$ & 0.037 \\
\hline & PB & $12.2 \pm 1.93$ & & $0.1 \pm 0.11$ & & $0.0 \pm 0.00$ & & $24.6 \pm 3.86$ & \\
\hline \multirow[t]{2}{*}{ May } & Control & $49.4 \pm 9.23$ & $<0.0001$ & $21.7 \pm 6.81$ & 0.012 & $0.0 \pm 0.00$ & - & $69.4 \pm 12.53$ & 0.0002 \\
\hline & PB & $14.7 \pm 2.42$ & & $5.9 \pm 1.58$ & & $0.0 \pm 0.00$ & & $18.9 \pm 2.88$ & \\
\hline \multirow[t]{2}{*}{ June } & Control & $54.9 \pm 6.99$ & $<0.0001$ & $41.7 \pm 16.37$ & $<0.0001$ & $0.0 \pm 0.00$ & - & $79.3 \pm 13.56$ & 0.0001 \\
\hline & PB & $23.7 \pm 2.28$ & & $7.5 \pm 2.09$ & & $0.0 \pm 0.00$ & & $28.6 \pm 3.06$ & \\
\hline \multirow[t]{2}{*}{ July } & Control & $15.0 \pm 3.19$ & 0.129 & $3.3 \pm 1.19$ & 0.279 & $3.8 \pm 1.85$ & 0.764 & $22.1 \pm 4.80$ & 0.393 \\
\hline & PB & $8.9 \pm 1.96$ & & $0.9 \pm 0.46$ & & $4.9 \pm 2.22$ & & $14.7 \pm 3.01$ & \\
\hline \multirow[t]{2}{*}{ August } & Control & $2.8 \pm 0.70$ & 0.463 & $5.4 \pm 1.92$ & 0.202 & $8.9 \pm 4.19$ & 0.129 & $17.1 \pm 5.48$ & 0.147 \\
\hline & PB & $1.7 \pm 0.51$ & & $1.4 \pm 0.44$ & & $3.1 \pm 1.19$ & & $6.3 \pm 1.61$ & \\
\hline \multirow[t]{2}{*}{ September } & Control & $1.1 \pm 0.32$ & 0.594 & $13.0 \pm 3.18$ & 0.028 & $15.3 \pm 4.35$ & 0.056 & $26.3 \pm 5.72$ & 0.033 \\
\hline & PB & $0.7 \pm 0.23$ & & $6.0 \pm 2.31$ & & $6.1 \pm 1.91$ & & $10.1 \pm 2.73$ & \\
\hline \multirow[t]{2}{*}{ October } & Control & $0.5 \pm 0.14$ & 0.699 & $0.9 \pm 0.33$ & 0.499 & $5.9 \pm 1.86$ & 0.611 & $6.9 \pm 1.94$ & 0.625 \\
\hline & PB & $0.3 \pm 0.11$ & & $0.2 \pm 0.11$ & & $7.4 \pm 4.28$ & & $7.7 \pm 4.29$ & \\
\hline
\end{tabular}

${ }^{1} P$ values reflect the comparison of tick burden on adult cows in PB and control pastures for each respective sampling period. 
common in Oklahoma (Semtner and Hair 1973; Zimmerman et al. 1987).

Time since burn did not play a major role when comparing tick burden on cows and calves in PB and control pastures. The first year of observations (2009) occurred just following a prescribed burn on the control pastures, which are burned entirely once every 3 yr. In this year, 2975 of $4332(68.7 \%)$ ticks were on animals in control pastures and only 1357 $(31.3 \%)$ ticks were on animals in PB pastures. In 2010, $1 \mathrm{yr}$ after a prescribed burn, animals in control pastures had 3998 of $5703(70.1 \%)$ ticks, whereas animals in PB pastures had only $1705(29.9 \%)$ ticks. In the final year of observation, animals in control pastures were infested with 2608 of 3574 $(73.0 \%)$ ticks and animals in PB pastures only had 966 $(27.0 \%)$ ticks. This slight increase in margin each year between $\mathrm{PB}$ and control pastures was expected, although we expected it to be more pronounced. As time progressed from the last prescribed fire application, control pastures accumulated more leaf litter and biomass that could have provided more suitable microhabitats that could have supported larger tick populations (Davidson et al. 1994). In contrast, leaf litter accumulation in PB pastures should be constant because subplots are burned on a rotating schedule.

The yearly changes in tick populations in control pastures were similar to findings in other burn regimen studies (Jacobson and Hurst 1979; Warren et al. 1987; Scifres et al. 1988; Davidson et al. 1994; Cully 1999; Allan 2009). Davidson et al. (1994) compared annual and biennial burn intervals on tick populations using cloth panel drags and $\mathrm{CO}_{2}$-baited traps. He found fewer free-living ticks on pastures burned annually than on pastures burned biennially. Cully (1999) also noted reduced tick abundance on annually burned plots but not on plots burned using a 4- or 20-yr burn interval. Longer burn intervals allow the reestablishment of the leaf litter layer and regrowth of larger, protective vegetation. This trend of pastures with longer times since burn supporting larger tick populations was observed in the present study in relation to the number of ticks parasitizing cattle as the time since burn increased in control pastures.

Application of PB in cattle pastures as done in the current study is also influenced by focal grazing of cattle (Fuhlendorf and Engle 2004), making direct comparisons to other studies that examined only the effects of fire difficult. Nonetheless, one difference observed in the present study compared to other work done with prescribed burning was the lack of an increase in A. americanum larvae. Allan (2009) noted an increase in A. americanum larvae $2 \mathrm{yr}$ after a fire event in Missouri. This increase was attributed to increased white-tailed deer browsing in burned areas. In our study, larvae remained lower in PB plots than in control pastures each year. This difference was likely due to a much lower success rates for oviposition and hatching in tall-grass prairies (our study) versus oak-hickory forest (Allan's study). Koch (1984) found A. americanum ticks had $100 \%$ oviposition success and $95 \%$ hatch success in upland oak-hickory habitat, whereas A. americanum in meadow habitat had $60 \%$ oviposition success and $0 \%$ hatch success during the same time period. This difference was driven by the dense leaf litter and overstory vegetation preventing direct sunlight from reaching the forest floor in oak-hickory forests, which provided more protection than in prairie habitats.
In addition to providing significant reductions in the number of ticks that infest cattle compared to other homogeneous burning regimens, $\mathrm{PB}$ is also considered a more sustainable practice. Applying fires too often can lead to detrimental changes in the soil chemistry (Duncan 2003). In a PB-treated pasture, vegetation receives a 3 -yr rest period between applications of prescribed burning (i.e., same return interval as the control pastures that were burned once every $3 \mathrm{yr}$ ). This regimen continually provides a freshly burned patch where cattle spend the majority of their time (Fuhlendorf and Engle 2004; Vermeire et al. 2004). However, older subplots in a PB pasture have re-established leaf litter and biomass, which create favorable tick habitat and prevent extirpation of ticks in $\mathrm{PB}$ pastures. This fire-grazing interaction is likely an important contributing factor to the observed pattern of reduced tick burdens on cattle in PB pastures.

Other studies have shown reduced weight gain caused by infestations with ticks (Scifres et al. 1988; Byford et al. 1992). In the present study, a weigh tape was used to estimate weights of calves because a livestock scale was not available for use throughout the study. Because of the inaccuracy of weigh tapes, it was likely that we might not have been able to detect a difference in ADG of calves in PB versus control pastures even if one existed. The relatively low stocking density and overall high plane of nutrition in our cattle also might have masked any adverse effects from tick feeding in the present study. Fuhlendorf and Engle (2004) also measured ADG of cattle on $\mathrm{PB}$ pastures using electronic livestock weigh scales. Using the same PB treatment/control pasture design as the present study, differences between $\mathrm{PB}$ and control pasture animals were not detected (Fuhlendorf and Engle 2004).

Application of $\mathrm{PB}$ to pastures significantly reduced the number of ticks on cattle. Although an increase in ADG in calves on PB-treated pastures was not observed, application of PB can be a useful tool for cattle producers to lower their dependence on chemical acaricides. Additionally, application of PB over a regimen of annual burns will not compromise soil chemistry, yet will still reduce the number of ticks on cattle.

Davidson et al. (1994) used two different burning regimens (annual and biennial) and monitored tick abundance with cloth drags and $\mathrm{CO}_{2}$-baited traps in central Georgia. They recorded reductions in the number of ticks in the most recently burned plots, which they associated with reduced litter depths. The most consistent reduction was associated with the number of larvae, which was thought to be correlated with impaired survival and oviposition of replete females. In the present study, there was no difference in the number of larvae found between recently burned subplots and older subplots. Cully (1999) also noted reduced tick abundance using cloth panel sampling on annually burned tall-grass prairie plots but did not see similar results when longer burn intervals were used. Cully (1999) demonstrated that microhabitats only remain inhospitable to ticks for about 1 to $2 \mathrm{yr}$ following a prescribed burn. This window where survival of ticks is negatively affected was not detected in the present study.

Significant differences in tick abundance between PB pastures and control pastures were not detected, nor were differences detected in the abundance of ticks among subplots within PB pastures. This lack of differences might have been caused by the sampling methodology used, because the 
effectiveness of cloth panel dragging is thought to vary with tick behavior, vegetation type (Petry et al. 2010), and environmental influences. For example, high temperatures stimulate ticks to migrate downwards and remain in leaf litter, which can prevent contact with cloth drags (Semtner et al. 1971). Furthermore, Barnard (1981) proposed that sampling the environment for ticks might not always provide the best representation of the number of ticks that feed on cattle. Populations of A. americanum ticks recovered from pastures with the use of cloth dragging or $\mathrm{CO}_{2}$ trapping did not reflect numbers gathered from assessing tick burden on cattle (Barnard 1981). It is possible that a similar phenomenon was detected in the present study because cattle in PB-treated pastures had fewer ticks than cattle in control pastures.

\section{IMPLICATIONS}

Previous studies have demonstrated that $\mathrm{PB}$, coupled with focal grazing of ruminants, creates variation in the composition and structure of the plant community that can be beneficial to cattle. In the present study, we demonstrated that cattle grazed in $\mathrm{PB}$ pastures were infested with fewer ticks than those in control pastures. Differences in tick infestation were observed in months of peak tick burden for both adult cows and calves. Adult ticks were reduced on cows in PB pastures in April, May, and June. Nymphs were reduced on cows May, June, and September, and larvae were reduced on calves in September. In addition to providing significant reductions in the number of ticks that infest cattle compared to other homogeneous burning regimens, $\mathrm{PB}$ is also considered a more sustainable practice and can be a useful tool for cattle producers to lower their dependence on chemical acaricides.

\section{ACKNOWLEDGMENTS}

We are grateful to Emily Thaden, Lacey Knapp, Nicole Morton, Andrea Blackwell, Anne Barrett, Sam Peplin, and Markie Schiller of the Center for Veterinary Health Science for help estimating tick abundance and tick burden on cattle, as well as Chris Stansberry and Adam Gourly for help processing cattle.

\section{LITERATURE CITED}

Allan, B. F. 2009. Influence of prescribed burn on the abundance of Amblyomma americanum (Acari: Ixodidae) in Missouri Ozarks. Journal of Medical Entomology 46:1030-1036.

Barker, R. W., A. A. Kocan, S. A. Ewing, R. P. Wettemann, and M. E. Payton. 2004. Occurrence of the Gulf Coast tick (Acari: Ixodidae) on wild and domestic mammals in north-central Oklahoma. Journal of Medical Entomology 41:170178.

Barnard, D. R. 1981. Amblyomma americanum: comparisons of populations of ticks free living on pasture and parasitic on cattle. Annuals of the Entomological Society of America 74:507-511.

BertRAnd, M. R., AND M. L. Wilson. 1997. Microhabitat-independent regional differences in survival of unfed Ixodes scapularis nymphs (Acari: Ixodidae) in Connecticut. Entomological Society of America 34:167-172.

Bloemer, S. R., R. H. Zimmerman, and K. Fairbanks 1988. Abundance, attachment sites, and density estimators of lone star ticks (Acari: Ixodidae) infesting white-tailed deer. Journal of Medical Entomology 25:295-300.
Byford, R. L., M. E. Crail, and B. L. Crosby. 1992. A review of ectoparasites and their effects on cattle production. Journal of Animal Science 70:597-602.

Chilton, N. B., AND C. M. BuLl. 1994. Influence of environmental factors on oviposition and egg development in Amblyomma libatum and Aponomma hydrosauri (Acari: Ixodidae). International Journal for Parasitology 24:83-90.

Clifford, C. M., G. Anastos, and A. Elbl. 1960. The larval ixodid ticks of the eastern United States. Miscellaneous Publications of the Entomological Society of America 2:215-244.

Clymer, B. C., D. E. Howell, and J. A. Hair. 1970. Animal hosts of economically important ticks (Acarina) in east-central Oklahoma. Annals of the Entomological Society of America 63:612-613.

Cully, J. F., JR. 1999. Lone star tick abundance, fire, and bison grazing in tallgrass prairie. Journal of Range Management 52:139-144.

Davidson, W. R., D. A. Siefken, and L. H. Creekmore. 1994. Influence of annual and biennial prescribed burning during March on the abundance of Amblyomma americanum (Acari: Ixodidae) in central Georgia. Journal of Medical Entomology 31:72-81.

de Catro, J. J., and R. M. Newson. 1993. Host resistance in cattle tick control. Parasitology Today 9:13-17.

de la Fuente, J., C. Almazan, M. Canales, J. M. Perez de la Lastra, K. M. Kocan, and P. WILLADSEN. 2007. A ten-year review of commercial vaccine performance for control of tick infestations on cattle. Animal Health Research Reviews 8:23-28.

Diamant, G., and R. K. StRickland. 1965. Manual on livestock ticks for animal disease eradication division personnel. Washington, DC, USA: US Government Printing Office. 142 p.

Drummond, R. O. 1987. Economic aspects of ectoparasites of cattle in North America. In: W. H. D. Learning and J. Guerrero [EDS.]. The economic impact of parasitism in cattle. Proceedings of the MSD AGVET Symposium XXIII of the World Veterinary Congress; 19 August 1987; Montreal, Canada; Lawrenceville, NJ, USA: Veterinary Learning Systems, Inc. p. 9-24.

Duncan, K. W. 2003. Considerations for prescribed burning. Texas Agricultural Experiment Station and Cooperative Extension. Available at: http://aces.nmsu. edu/pubs/_circulars/Cr-522.pdf. Accessed 13 June 2012.

Funlendorf, S. D., AND D. M. Engle. 2004. Application of the fire-grazing interaction to restore a shifting mosaic on tallgrass prairie. Journal of Applied Ecology 41:604614.

George, J. E., J. M. Pound, And R. B. Davey. 2004. Chemical control of ticks on cattle and the resistance of these parasites to acaricides. Parasitology 129:S353S366.

Graf, J. F., R. Gogolewski, N. Leach-Bing, G. A. Sabatini, M. B. Molento, E. L. Bordin, and G. J. Arantes. 2004. Tick control: an industry point of view. Parasitology 129:S427-S442.

Harlan, H. J., And W. A. Foster. 1986. Temperature effects on host-seeking by larval American dog ticks, Dermacentor variabilis (Say). Ohio Journal of Science 86:210-212.

Harlan, H. J., and W. A. Foster. 1990. Micrometeorological factors affecting hostseeking activity of adult Dermacentor variabilis (Acari: Ixodidae). Entomological Society of America 27:471-479.

JacoBson, H. A., And G. A. HuRst. 1979. Prevalence of parasitism by Amblyomma americanum on wild turkey poults as influenced by prescribed burning. Journal of Wildlife Diseases 15:43-47.

Jongejan, F., and G. Ullenberg. 2004. The global importance of ticks. Parasitology 129:S3-S14.

Jonsson, N. N., D. G. Mayer, A. L. Matschoss, P. E. Green, and J. Ansell. 1998. Production effects of cattle tick (Boophilus microplus) infestation of high yielding dairy cows. Veterinary Parasitology 78:65-77.

Keirans, J. E., and L. A. DuRden. 1998. Illustrated key to nymphs of the tick genus Amblyomma (Acari: Ixodidae) found in the United States. Journal of Medical Entomology 35:489-495.

Keirans, J. E., AND T. R. LitwaK. 1988. Pictorial key to the adults of hard ticks, family Ixodidae (Ixodida: Ixodoidea), east of the Mississippi River. Journal of Medical Entomology 26:435-448.

Косн, H. G. 1984. Survival of the lone star tick, Amblyomma americanum (Acari: Ixodidae), in contrasting habitats and different years in southeastern Oklahoma, USA. Journal of Medical Entomology 21:69-79. 
Kollars, T. M., J. H. Oliver, L. A. Durden, and P. G. Kollars. 2000. Host associations and seasonal activity of Amblyomma americanum (Acari: Ixodidae) in Missouri. Journal of Parasitology 86:1156-1159.

Lohmeyer, K. H., J. A. Mlller, J. M. Pound, and D. D. Oehler. 2009. Efficacy of eprinomectin and doramectin against Amblyomma americanum (Acari: Ixodidae) on cattle. Journal of Economic Entomology 102:809-814.

Needham, G. R., and P. D. Teel. 1991. Off-host physiological ecology of ixodid ticks. Annual Review of Entomology 36:659-681.

Petry, W. K., S. A. Fore, L. J. Fielden, And H. J. Kim. 2010. A quantitative comparison of two sample methods for collecting Amblyomma americanum and Dermacentor variabilis (Acari: Ixodidae) in Missouri. Experimental and Applied Acarology 52:427-438.

Robertson, S. A., C. D. Patrick, P. J. Semtner, and J. A. Hair. 1975. The ecology and behavior of the lone star tick (Acarina: Ixodidae). VI. Response of unfed adults to certain environmental parameters. Journal of Medical Entomology 12:525-529.

Schulze, T. L., AND R. A. JoRdan. 2003. Meteorologically mediated diurnal questing of Ixodes scapularis and Amblyomma americanum (Acari: Ixodidae) nymphs. Journal of Medical Entomology 40:395-402.

Scifres, C. J., T. W. Oldham, P. D. Teel, and D. L. Drawe. 1988. Gulf coast tick (Amblyomma maculatum) populations and responses to burning of coastal prairie habitats. Southwestern Naturalist 33:56-64.

Semtner, P. J., R. W. Barker, and J. A. Hair. 1971. The ecology and behavior of the Ione star tick (Acarina: Ixodidae). II. Activity and survival in different ecological habitats. Journal of Medical Entomology 8:719-725.

SemtneR, P. J., AND J. A. Halr. 1973. Distribution, seasonal abundance, and hosts of the gulf coast tick in Oklahoma. Annals of the Entomological Society of America 66:1264-1268.
Stacey, B. R., R. E. Williams, R. G. Buckner, and J. A. Halr. 1978. Changes in weight and blood composition of Hereford and Brahman steers in drylots and infested with adult gulf coast ticks. Journal of Economic Entomology 71:967-970.

Strickland, R. K., R. R. Gerriah, J. L. Hourrington, and G. O. Schubert. 1976. Ticks of veterinary importance. Washington, DC, USA: Animal and Plant Health Inspection Service, US Department of Agriculture. $122 \mathrm{p}$.

Tolleson, D. R., P. D. Teel, J. W. Stuth, 0. F. Strey, T. H. Welsh, JR., G. E. Carstens, M. T. LongneCker, K. K. BaniK, and S. D. Prince. 2010. Effects of a lone star tick (Amblyomma americanum) burden on performance and metabolic indicators in growing beef steers. Veterinary Parasitology 173:99-106.

Vermeire, L. T., R. B. Mitchell, S. D. Fuhlendorf, and R. L. Gillen. 2004. Patch burning effects on grazing distribution. Journal of Range Management 57:248-252.

Warren, S. D., C. J. Scifres, and P. D. Teel. 1987. Response of grassland arthropods to burning: a review. Agriculture, Ecosystems, and Environment 19:105-130.

Willadsen, P. 2006. Tick control: thoughts on a research agenda. Veterinary Parasitology 138:161-168.

Williams, R. E., J. A. Hair, and R. W. McNew. 1978. Effects of gulf coast ticks on blood composition and weights of pastured hereford steers. Journal of Parasitology 64:336-342.

Wright, R. E., and R. W. Barker. 2006. Common ticks of Oklahoma and tick-borne diseases. Oklahoma Cooperative Extension Service F-7001:1-8.

Zimmerman, R. H., G. R. McWherter, and S. R. Bloemer. 1987. Role of small mammals in population dynamics and dissemination of Amblyomma americanum and Dermacentor variabilis (Acari: Ixodidae) at Land-Between-The-Lakes, Tennessee. Journal of Medical Entomology 24:370-375. 